\section{Characterization of Instructor and Student Behaviors in CURE and Non- CURE Learning Environments: Impacts on Student Motivation, Science Identity Development, and Perceptions of the Laboratory Experience}

David Esparza, ${ }^{\dagger}$ Amy E. Wagler, ${ }^{\ddagger}$ and Jeffrey T. Olimpo ${ }^{\dagger *}$

${ }^{\dagger}$ Department of Biological Sciences and "Department of Mathematical Sciences, The University of Texas at El Paso, El Paso, TX 79968

\begin{abstract}
Course-based undergraduate research experiences (CUREs) serve to increase student access to authentic scientific opportunities. Current evidence within the literature indicates that engagement in CUREs promotes students' science identity development, science self-efficacy, motivation, and ability to "think like a scientist." Despite the importance of these findings, few studies have examined the behaviors and interactions occurring within CURE and non-CURE settings and the impact of those behaviors on said student outcomes. To address these concerns, we conducted a mixed-methods study to explore student and instructor behaviors in four CURE and four non-CURE introductory biology laboratory sections. Representative video data were collected in each section and coded using the Laboratory Observation Protocol for Undergraduate STEM. In addition, pre/postsemester affective survey data were obtained from CURE and non-CURE participants. Results indicated that CURE students and instructors engaged in more interactive behaviors (e.g., oneon-one dialogue, questioning) than their non-CURE counterparts, a finding confirmed by analyzing behavioral patterns via construction of partial correlation networks. Multiple regression analyses further revealed that both student and instructor interactive behaviors and enrollment in a CURE were strong predictors of pre/postsemester shifts in student motivation, science identity development, collaboration, and perceived opportunities to make relevant scientific discoveries.
\end{abstract}

\section{INTRODUCTION}

National efforts to reform postsecondary laboratory education in the science, technology, engineering, and mathematics (STEM) disciplines have emphasized the importance of engaging students in the authentic process of scientific discovery (National Research Council, 2003; National Science Foundation, 2003; American Association for the Advancement of Science, 2011; National Academies of Sciences, Engineering, and Medicine, 2017). In contrast to traditional laboratory curricula, which have historically been described as prescriptive in nature (Germann et al., 1996; Brownell et al., 2012), discovery-based approaches aim to immerse learners in scientific practices that involve generating hypotheses, designing experiments, analyzing data, and disseminating findings to the broader community (Auchincloss et al., 2014; Spell et al., 2014). In recent years, course-based undergraduate research experiences (CUREs) have emerged as an accessible and inclusive platform to achieve this goal. Current evidence within the biology education literature indicates that CUREs are effective at promoting students' researcher self-efficacy, science identity development, and persistence in the
Graham F. Hatfull, Monitoring Editor Submitted Apr 30, 2019; Revised Nov 21, 2019; Accepted Nov 27, 2019

CBE Life Sci Educ March 1, 2020 19:ar10 DOI:10.1187/cbe.19-04-0082

*Address correspondence to: Jeffrey T. Olimpo (jtolimpo@utep.edu)

(c) 2020 D. Esparza et al. CBE-Life Sciences Education $\odot 2020$ The American Society for Cell Biology. This article is distributed by The

American Society for Cell Biology under license from the author(s). It is available to the public under an Attribution-Noncommercial-Share Alike 3.0 Unported Creative Commons License (http://creativecommons.org/licenses/ by-nc-sa/3.0).

"ASCB®" and "The American Society for Cell Biology $\circledR^{\prime \prime}$ are registered trademarks of The American Society for Cell Biology. 
domain (Brownell et al., 2012; Gasper and Gardner, 2013; Corwin et al., 2015; Olimpo et al., 2016, 2019; Rodenbusch et al., 2016). In addition, students who participate in CUREs demonstrate marked increases in their ability to conduct research and, more broadly, to "think like a scientist" (Brownell et al., 2015).

Despite the imperative nature of these findings, however, relatively few studies have examined the contextual features inherent to CURE and non-CURE learning environments that promote students' academic and professional growth in such contexts (e.g., Bond-Robinson and Rodriques, 2006; Velasco et al., 2016). In an effort to address these concerns, we adopted a mixed-methods approach to examine the following questions:

1. What typical, interactive, and noninstructive behaviors do instructors and students exhibit within CURE and non-CURE sections of an introductory cell and molecular biology laboratory course?

2. To what extent are those behaviors similar or dissimilar between course contexts?

3. What impact do student and instructor behaviors have on student motivation, science identity development, and perceptions of their respective laboratory experience, after controlling for participant demographics and course context?

We hypothesized that CURE students and instructors would exhibit more interactive behaviors (e.g., posing questions, oneon-one talk) than their non-CURE counterparts given the active and research-driven nature of the course. This assertion is supported by existing literature, which demonstrates, for instance, that student behaviors are influenced by the level of inquiry in STEM laboratory exercises (Hofstein and Lunetta, 2004; Xu and Talanquer, 2013). Furthermore, prior work in the field indicates that student engagement in the learning process positively impacts both cognitive and affective outcomes, leading to overall favorable perceptions of the learning environment (Watkins and Mazur, 2013; Freeman et al., 2014; Galloway et al., 2016; Olimpo et al., 2016). We therefore anticipated that, in both CURE and non-CURE contexts, increased frequency of interactive behaviors (whether originating from the student[s] or the instructor) would result in a proportional increase in student motivation, science identity development, and positive perceptions of the laboratory experience.

\section{CONCEPTUAL FRAMEWORK}

The study presented here is situated within Cohen and Ball's (1999) conceptual framework for instructional capacity. In this framework, instructional practices are viewed as a multifaceted composite of interaction events between educators, students, and pedagogical materials present within the classroom environment. Accordingly, each of the aforementioned elements has an equal impact on the learning process and the targeted learning outcomes established for the course. With respect to our own research, we contend that use of this framework offers an effective means to compare and contrast instructor and student behaviors evidenced in CURE and non-CURE laboratories, as it does not presume that instruction is uniform between each of those contexts or among courses of the same instructional type. Furthermore, and in concert with prior evidence in the field (see Velasco et al., 2016), adopting an instructional capacity lens acknowledges that the broader parameters governing one's learning environment (e.g., the expository nature of non-CURE laboratory experiences) have the potential to influence instructor and student outcomes within said environments, including the types of interactions that occur as well as shifts in attitude, motivation, and professional identity among participants. Given our explicit focus on such outcomes and the larger context surrounding them, we anticipate that our findings will be of practical relevance to those individuals responsible for developing, facilitating, and evaluating diverse laboratory experiences across a wide array of disciplines. Moreover, the existent corpus of literature regarding CUREs in the biological sciences has historically focused on student outcomes and/or descriptions of authentic research experiences. While these contributions are imperative to our understanding of CUREs, fewer articles have examined instructor dimensions (e.g., Shortlidge et al., 2015). Thus, we contend that Cohen and Ball's (1999) framework offers a critical reminder of the importance of the instructor within the learning environment and, as such, offers a lens through which we can objectively examine an often-overlooked component of the CURE teaching and learning process.

\section{METHODS \\ Course Contexts}

CURE $(n=4)$ and non-CURE $(n=4)$ sections involved in this research constitute a representative sample of all introductory cell and molecular biology laboratory course sections offered at a midsize, research-intensive institution in the Southwest. Characteristic of Auchincloss et al.'s (2014) framework, students enrolled in CURE sections of the course formulated novel research questions and developed testable hypotheses, designed their experiments, collected and analyzed data, and communicated the outcomes of their studies to the university community (see also Spell et al., 2014; Olimpo et al., 2016). Additionally, it is important to note that the content covered in the CURE sections was centered on the research topics of associated faculty within the biological sciences department (more information can be found at http://fyris.utep.edu) and had little to no relation to what was taught in the associated lecture portion of the course. In contrast, the laboratory activities and content covered in the non-CURE sections were aligned with the major topics covered in the corresponding lecture course (Gonzalez, 2019). Table 1 provides a comprehensive description of all CURE and non-CURE sections in which data were collected.

\section{Instructor Recruitment and Selection Process}

The graduate teaching assistant instructors (hereafter referred to only as "instructors") facilitating the CURE and non-CURE sections of the introductory cell and molecular biology laboratory course were invited to participate in the research. Instructors are typically selected to teach CUREs when the course research topic closely aligns with their respective research expertise. Thus, graduate students whose advisors are offering a CURE are often responsible for teaching these sections, with consideration given to their teaching expertise and availability of funding and time. In contrast, all non-CURE instructors were selected to teach their respective labs based on teaching expertise and availability of funding and time. For the purposes of this study, CURE and non-CURE instructors were required to provide basic demographic information regarding their educational backgrounds and teaching experience. We likewise asked 
TABLE 1. Contextual information for the CURE and non-CURE laboratory sections

\begin{tabular}{|c|c|c|c|c|c|}
\hline Descriptor & Virology CURE & Brain Mapping CURE & $\begin{array}{c}\text { Evolutionary } \\
\text { Genetics CURE }\end{array}$ & $\begin{array}{c}\text { Zoonotic Diseases } \\
\text { CURE }\end{array}$ & $\begin{array}{l}\text { Non-CURE laboratory } \\
\text { sections }\end{array}$ \\
\hline Class size & $n=12$ & $n=14$ & $n=8$ & $n=13$ & $n=16$ (on average) \\
\hline Meeting schedule & $\begin{array}{l}\text { Twice weekly, } \\
3 \text { hours/session }\end{array}$ & $\begin{array}{l}\text { Twice weekly, } \\
3 \text { hours/session }\end{array}$ & $\begin{array}{l}\text { Twice weekly, } \\
3 \text { hours/session }\end{array}$ & $\begin{array}{l}\text { Twice weekly, } \\
3 \text { hours/session }\end{array}$ & $\begin{array}{l}\text { Once weekly, } \\
2 \text { hours/session }\end{array}$ \\
\hline Level of inquiry ${ }^{\mathrm{a}}$ & 3 & 3 & 3 & 3 & 0 \\
\hline \multirow[t]{4}{*}{ Learning objectives } & $\begin{array}{l}\text { Understand basic } \\
\text { concepts of } \\
\text { virus-host } \\
\text { interactions, } \\
\text { cellular pathways, } \\
\text { and mitochondrial } \\
\text { morphology }\end{array}$ & $\begin{array}{l}\text { Understand basic } \\
\text { concepts of } \\
\text { neuroanatomy, } \\
\text { neurotransmitter } \\
\text { localization, } \\
\text { neural pathways, } \\
\text { and neuronal } \\
\text { physiology }\end{array}$ & $\begin{array}{l}\text { Understand basic } \\
\text { concepts of } \\
\text { molecular genetics } \\
\text { (e.g., transcrip- } \\
\text { tion, translation, } \\
\text { PCR), evolution, } \\
\text { tree-thinking skills, } \\
\text { and conservation } \\
\text { biology }\end{array}$ & $\begin{array}{l}\text { Understand basic } \\
\text { concepts in } \\
\text { cellular biology } \\
\text { (e.g., macromole- } \\
\text { cules, osmosis, cell } \\
\text { structure) and } \\
\text { bacterial evolution }\end{array}$ & $\begin{array}{l}\text { Understand and } \\
\text { demonstrate the } \\
\text { basic concepts of } \\
\text { cell and molecular } \\
\text { biology that are } \\
\text { covered within the } \\
\text { biology lecture } \\
\text { course }\end{array}$ \\
\hline & $\begin{array}{l}\text { Develop familiarity in } \\
\text { laboratory } \\
\text { techniques for cell } \\
\text { culture, transfec- } \\
\text { tion, Western } \\
\text { blotting, and } \\
\text { cellular imaging }\end{array}$ & $\begin{array}{l}\text { Develop familiarity in } \\
\text { laboratory } \\
\text { techniques for } \\
\text { Nissl staining, } \\
\text { microtome use, } \\
\text { and brain } \\
\text { parcellation }\end{array}$ & $\begin{array}{l}\text { Develop familiarity in } \\
\text { laboratory } \\
\text { techniques for } \\
\text { DNA isolation, } \\
\text { purification, and } \\
\text { sequencing }\end{array}$ & $\begin{array}{l}\text { Develop familiarity in } \\
\text { laboratory } \\
\text { techniques for cell } \\
\text { culture, co-infec- } \\
\text { tion, ELISA, and } \\
\text { cellular imaging }\end{array}$ & $\begin{array}{l}\text { Develop familiarity } \\
\text { with basic } \\
\text { laboratory } \\
\text { techniques and } \\
\text { laboratory safety }\end{array}$ \\
\hline & $\begin{array}{l}\text { Gain foundational } \\
\text { knowledge in } \\
\text { writing and } \\
\text { reading scientific } \\
\text { literature and in } \\
\text { scientific } \\
\text { presentation skills }\end{array}$ & $\begin{array}{l}\text { Gain foundational } \\
\text { knowledge in } \\
\text { writing and } \\
\text { reading scientific } \\
\text { literature and in } \\
\text { scientific } \\
\text { presentation skills }\end{array}$ & $\begin{array}{l}\text { Gain foundational } \\
\text { knowledge in } \\
\text { writing and } \\
\text { reading scientific } \\
\text { literature and in } \\
\text { scientific } \\
\text { presentation skills }\end{array}$ & $\begin{array}{l}\text { Gain foundational } \\
\text { knowledge in } \\
\text { writing and } \\
\text { reading scientific } \\
\text { literature and in } \\
\text { scientific } \\
\text { presentation skills }\end{array}$ & $\begin{array}{l}\text { Gain foundational } \\
\text { knowledge in } \\
\text { writing and reading } \\
\text { scientific literature } \\
\text { and in scientific } \\
\text { presentation skills. }\end{array}$ \\
\hline & $\begin{array}{l}\text { Demonstrate } \\
\text { proficiency in } \\
\text { experimental } \\
\text { design, an } \\
\text { understanding of } \\
\text { the scientific } \\
\text { process, and } \\
\text { statistical analysis } \\
\text { within the context } \\
\text { of virology }\end{array}$ & $\begin{array}{l}\text { Demonstrate } \\
\text { proficiency in } \\
\text { experimental } \\
\text { design, an } \\
\text { understanding of } \\
\text { the scientific } \\
\text { process, and } \\
\text { statistical analysis } \\
\text { within the context } \\
\text { of systems } \\
\text { neuroscience }\end{array}$ & $\begin{array}{l}\text { Demonstrate } \\
\text { proficiency in } \\
\text { experimental } \\
\text { design, an } \\
\text { understanding of } \\
\text { the scientific } \\
\text { process, and } \\
\text { statistical analysis } \\
\text { within the context } \\
\text { of evolutionary } \\
\text { genetics }\end{array}$ & $\begin{array}{l}\text { Demonstrate } \\
\text { proficiency in } \\
\text { experimental } \\
\text { design and an } \\
\text { understanding of } \\
\text { the scientific } \\
\text { process within the } \\
\text { context of } \\
\text { molecular biology }\end{array}$ & $\begin{array}{l}\text { Demonstrate an } \\
\text { understanding of } \\
\text { the scientific } \\
\text { process within the } \\
\text { context of cellular } \\
\text { and molecular } \\
\text { biology }\end{array}$ \\
\hline
\end{tabular}

anquiry levels were determined in accordance with criteria established by Fay et al. (2007).

instructors to complete the STEM Teaching Self-Efficacy Scale (DeChenne et al., 2012) and Approaches to Teaching Inventory (Trigwell and Prosser, 2004; Table 2). Collectively, this information allowed us to account for variation in teaching self-efficacy, pedagogical style, and teaching experience of the instructors and thus reduced the influence of such confounding factors on our analyses. Independent-samples $t$ tests revealed no betweengroup differences in outcome on either measure $(p \geq 0.134$ for all comparisons). Demographic characteristics (e.g., educational background, prior pedagogical training and professional development) were likewise found to be relatively homogeneous between groups (Table 2).

\section{Student Recruitment and Selection Process}

Student participants $(N=107)$ represented a convenience sample consisting of all individuals enrolled in each of four CURE $(n=47)$ or four non-CURE $(n=64)$ sections described earlier (see Course Contexts). Enrollment in these courses was voluntary with the exception that students receiving support through the university's BUILDing SCHOLARS initiative (https://buildingscholars.utep.edu/web) were required to complete one or more CUREs as part of their program requirements. While CUREs in the biological sciences were not the only option to meet this requirement, a subset of BUILD students was enrolled in the CUREs involved in this research. Importantly, however, they were not assigned to any particular CURE section. Collectively, participants were predominantly female (62\%), Hispanic or Latin@ (90\%), and majoring in one of the STEM disciplines (68\%; Table 3). In an effort to reduce selection bias, only those students enrolled in the laboratory course for the first time and who completed all aspects of the data-collection protocol were included in our analyses. Participants were not selected or excluded on the basis of any other qualifying factors.

This research was approved by The University of Texas at El Paso's Institutional Review Board under protocol 789648. 
TABLE 2. Demographic characteristics for CURE and non-CURE instructors

\begin{tabular}{|c|c|c|}
\hline Category & $\begin{array}{c}\text { CURE } \\
\text { instructors }\end{array}$ & $\begin{array}{l}\text { Non-CURE } \\
\text { instructors }\end{array}$ \\
\hline \multicolumn{3}{|l|}{ Educational background ${ }^{\mathrm{a}}$} \\
\hline Cell/molecular biology & 100.0 & 100.0 \\
\hline Ecology/evolutionary biology & 0.0 & 0.0 \\
\hline Semesters of teaching experience (total) ${ }^{\mathrm{b}}$ & $5.5(0.7)$ & $4.3(0.6)$ \\
\hline \multicolumn{3}{|l|}{ Pedagogical background ${ }^{\mathrm{a}}$} \\
\hline Prior pedagogical training & 0.0 & 0.0 \\
\hline No prior pedagogical training & 100.0 & 100.0 \\
\hline \multicolumn{3}{|l|}{ Gender $^{\mathrm{a}}$} \\
\hline Male & 50.0 & 50.0 \\
\hline Female & 50.0 & 50.0 \\
\hline \multicolumn{3}{|l|}{ Approaches to Teaching Inventory ${ }^{b}$} \\
\hline Student-centered approaches & $35.0(1.0)$ & $28.8(3.5)$ \\
\hline Teacher-centered approaches & $26.8(4.8)$ & $29.3(2.5)$ \\
\hline \multicolumn{3}{|l|}{ STEM teaching self-efficacy ${ }^{\mathrm{b}}$} \\
\hline Learning & $5.5(0.2)$ & $5.2(0.3)$ \\
\hline Instructional & $5.4(0.3)$ & $5.1(0.3)$ \\
\hline
\end{tabular}

aValues are reported as percentages.

bValues are reported as M (SEM).

TABLE 3. Demographic characteristics for CURE and non-CURE student participants

\begin{tabular}{lcc}
\hline Category & $\begin{array}{c}\text { CURE } \\
\text { participants (\%) }\end{array}$ & $\begin{array}{c}\text { Non-CURE } \\
\text { participants (\%) }\end{array}$ \\
\hline Class standing & & \\
$\quad$ Freshman & 76.6 & 71.9 \\
$\quad$ Sophomore & 21.3 & 26.6 \\
$\quad$ Junior & 2.1 & 1.5 \\
$\quad$ Senior & 0.0 & 0.0 \\
Major & & \\
$\quad$ STEM & 87.2 & 54.7 \\
$\quad$ Non-STEM & 12.8 & 43.3 \\
Gender & & \\
$\quad$ Male & 38.3 & 37.5 \\
$\quad$ Female & 61.7 & 62.5 \\
Minority status & & \\
$\quad$ Caucasian & 8.5 & 10.9 \\
$\quad$ Non-Caucasian & 91.5 & 89.1 \\
First-generation status & & \\
$\quad$ First generation & 36.2 & 35.9 \\
$\quad$ Continuing generation & 63.8 & 64.1 \\
High school biology & & \\
$\quad$ General biology & 70.2 & 26.6 \\
Honors/AP biology & 29.8 & \\
\hline
\end{tabular}

${ }^{a}$ Major determination was made in accordance with guidelines published by the National Science Foundations' Louis Stokes Alliance for Minority Participation (LSAMP) initiative (www.lsamp.org/help/help_stem_cip_2015.cfm).

\section{Instruments}

Laboratory Observation Protocol for Undergraduate STEM. The Laboratory Observation Protocol for Undergraduate STEM (LOPUS) was used to identify and compare student and instructor behaviors (Velasco et al., 2016), as evidenced within CURE and non-CURE learning environments. As characterized by Velasco and colleagues (2016), the LOPUS coding scheme includes 12 student actions and 13 instructor actions that are broadly categorized as being either typical, interactive, or noninstructive in nature. We modified the LOPUS to include two additional criteria: 1) within-group student interaction (WG) and 2) betweengroup student interaction (BG), as previous research has demonstrated the importance of such behaviors in promoting student learning and success in STEM laboratory contexts (e.g., Okebukola, 1984; Shibley and Zimmaro, 2002). Specifically, these criteria allow for documentation of instances when a student is interacting with other students in his or her assigned laboratory group (WG) and/or when a student is interacting with a student outside of his or her assigned laboratory group (BG). We did not make use of the verbal interactions coding criteria, as consent was not obtained from all participants to collect audio-recorded data, and we removed the "Other" criterion in both the instructor and student protocols due to its lack of utility in discerning concrete behavioral patterns among participants. To determine the frequency of each behavior, we recorded the presence or absence of said behaviors within 2-minute intervals throughout the duration of each teaching episode. Observational data obtained from employing the LOPUS were then reported as the median percentage of time the instructor and students engaged in each relevant activity (i.e., LOPUS code) during class (Velasco et al., 2016).

Biology Motivation Questionnaire. To evaluate students' motivation over the course of the semester, we administered the Biology Motivation Questionnaire (Glynn et al., 2011). We selected this instrument intentionally given its previous use in examining shifts in student motivation within both traditional and active-learning contexts, including CUREs (e.g., Olimpo et al., 2016). The Biology Motivation Questionnaire consists of 25 Likert-item statements designed to assess five dimensions: 1) intrinsic motivation, 2) career motivation, 3) self-determination, 4) self-efficacy, and 5) grade motivation. Participants record their responses to each item using a five-point Likert scale ranging from strongly disagree (0) to strongly agree (4). Mean scores for each dimension are subsequently calculated, with higher mean scores indicating greater motivation within the specified dimension.

Science Identity Scale. Participants' science identity development was assessed using the Science Identity Scale (Estrada et al., 2011), which consists of five statements designed to examine respondents' sense of belonging to a community of scientists and the extent to which they perceive themselves to be scientists. We selected the Science Identity Scale intentionally given its extensive prior use in evaluating CURE and nonCURE students' science identity development (e.g., Fuchs et al., 2016) as well as its broader utility in examining science identity development among historically marginalized populations within STEM (Hernandez et al., 2013, 2018; Estrada et al., 2016). Responses are recorded on a five-point Likert scale ( $1=$ strongly disagree; 5 = strongly agree), and average scores for each item are tabulated. 
TABLE 4. Comparison of instructor and student behaviors in CURE and non-CURE contexts, as characterized by the LOPUS

\begin{tabular}{|c|c|c|c|c|}
\hline Category & $\begin{array}{l}\text { Non-CURE } \\
\text { (median) }^{\text {a }}\end{array}$ & $\begin{array}{c}\text { CURE } \\
\text { (median) }\end{array}$ & $\begin{array}{c}\text { Mann-Whitney } \\
U \\
\end{array}$ & $p$ value ${ }^{b}$ \\
\hline \multicolumn{5}{|l|}{ Student behaviors } \\
\hline \multicolumn{5}{|l|}{ Typical behaviors } \\
\hline Listening to instructor (L) & $21 \%$ & $33 \%$ & 188.50 & 0.040 \\
\hline Performing laboratory exercise (Lab) & $69 \%$ & $76 \%$ & 271.00 & 0.726 \\
\hline Test/quiz (TQ) & $6 \%$ & $0 \%$ & 47.00 & $<0.001$ \\
\hline \multicolumn{5}{|l|}{ Interactive behaviors } \\
\hline Individual student/group asking instructor a question with class listening (SQ) & $0 \%$ & $3 \%$ & 111.00 & $<0.001$ \\
\hline Individual student/group asking instructor a question (X1) & $9 \%$ & $21 \%$ & 166.50 & 0.012 \\
\hline Whole-class discussion (WC) & $2 \%$ & $10 \%$ & 186.50 & 0.035 \\
\hline Making predictions (Prd) & $0 \%$ & $2 \%$ & 169.00 & 0.004 \\
\hline Giving a presentation (SP) & $0 \%$ & $0 \%$ & 240.00 & 0.039 \\
\hline Initiating one-on-one interaction with the instructor (SI) & $11 \%$ & $26 \%$ & 144.00 & 0.003 \\
\hline Students interacting with other students in their groups (WG) & $75 \%$ & $82 \%$ & 255.50 & 0.503 \\
\hline Students interacting with peers in another group (BG) & $12 \%$ & $37 \%$ & 185.50 & 0.034 \\
\hline \multicolumn{5}{|l|}{ Noninstructive behaviors } \\
\hline Waiting (W) & $0 \%$ & $5 \%$ & 194.00 & 0.045 \\
\hline \multicolumn{5}{|l|}{ Instructor behaviors } \\
\hline \multicolumn{5}{|l|}{ Typical behaviors } \\
\hline Lecturing to class (Lec) & $9 \%$ & $26 \%$ & 165.00 & 0.011 \\
\hline Real-time writing on the board (RtW) & $0 \%$ & $14 \%$ & 134.00 & $<0.001$ \\
\hline Providing follow-up/feedback (FUp) & $0 \%$ & $4 \%$ & 164.50 & 0.003 \\
\hline Demonstration or video (DV) & $7 \%$ & $9 \%$ & 274.50 & 0.779 \\
\hline Monitoring the class/groups (M) & $39 \%$ & $23 \%$ & 150.50 & 0.004 \\
\hline \multicolumn{5}{|l|}{ Interactive behaviors } \\
\hline Posing a nonrhetorical question (PQ) & $2 \%$ & $12 \%$ & 189.50 & 0.042 \\
\hline Talking to students/groups one-on-one (Tlk) & $36 \%$ & $63 \%$ & 183.00 & 0.030 \\
\hline Posing a question to individual student or group of students (TPQ) & $6 \%$ & $22 \%$ & 105.00 & $<0.001$ \\
\hline Initiating one-on-one interaction with individual student or group of students (TI) & $24 \%$ & $48 \%$ & 144.00 & 0.003 \\
\hline \multicolumn{5}{|l|}{ Noninstructive behaviors } \\
\hline Performing administrative tasks (Adm) & $35 \%$ & $16 \%$ & 122.50 & 0.001 \\
\hline Waiting (W/W.1) & $13 \%$ & $0 \%$ & 128.00 & 0.001 \\
\hline
\end{tabular}

avalues represent the median of the percentage of time spent on various activities over six laboratory sessions. They do not add up to $100 \%$, because multiple behaviors can be observed during any 2-minute interval.

bPlease note that for both instructor and student behaviors, alpha was established a priori at 0.050 , and a Bonferroni correction was applied to adjust for multiple comparisons, where $\alpha_{\text {student adjusted }}=0.0042$ and $\alpha_{\text {instructor adjusted }}=0.0045$.

Laboratory Course Assessment Survey. In addition to examining the previously referenced noncognitive student outcomes, we furthermore sought to understand the perceptions students possessed regarding their experience in the CURE or non-CURE laboratory sections in which they were enrolled. Accordingly, we administered the Laboratory Course Assessment Survey (Corwin et al., 2015), which is designed to evaluate the extent to which individuals believe their laboratory course promoted collaboration, discovery, and iteration. Responses to the 17-question inventory are provided using a Likert scale, and mean scores are calculated for each dimension.

\section{Data Collection and Analysis}

Student and Instructor Behaviors. In an effort to generate a representative account of behavioral practices in each CURE and non-CURE section of the laboratory course, participants were video-recorded six times throughout the duration of the semester. This resulted in the collection of approximately 96 hours of video, with the average length of each recording being 110 minutes in length. Each video was coded inde- pendently by two researchers (including D.E.) with expertise in the biological sciences and biology education who used the LOPUS coding scheme (Velasco et al., 2016) to identify student and instructor behaviors evidenced within the video data set. High interrater reliability was observed between coders $(\kappa=$ 0.940; $p<0.001$ ), with all disputes resolved by a third researcher (J.O.) with expertise in science education. Mann-Whitney $U$-tests were performed to examine differences in CURE and non-CURE instructor behaviors as well as, similarly, student behaviors across contexts. For both instructor and student behaviors, alpha was established a priori at 0.050, and a Bonferroni correction was applied to adjust for multiple comparisons. Eleven instructor behaviors (see Table 4; Bonferroni correction: $p<0.0045$ ) and twelve student behaviors (see Table 4; Bonferroni correction: $p<0.0042$ ) were evaluated. SPSS (v. 23; IBM, Armonk, NY) was used to perform all statistical analyses.

Partial Correlation Networks of Instructor and Student Behaviors. In addition to comparing differences in the frequency of instructor and student behaviors between CURE and 


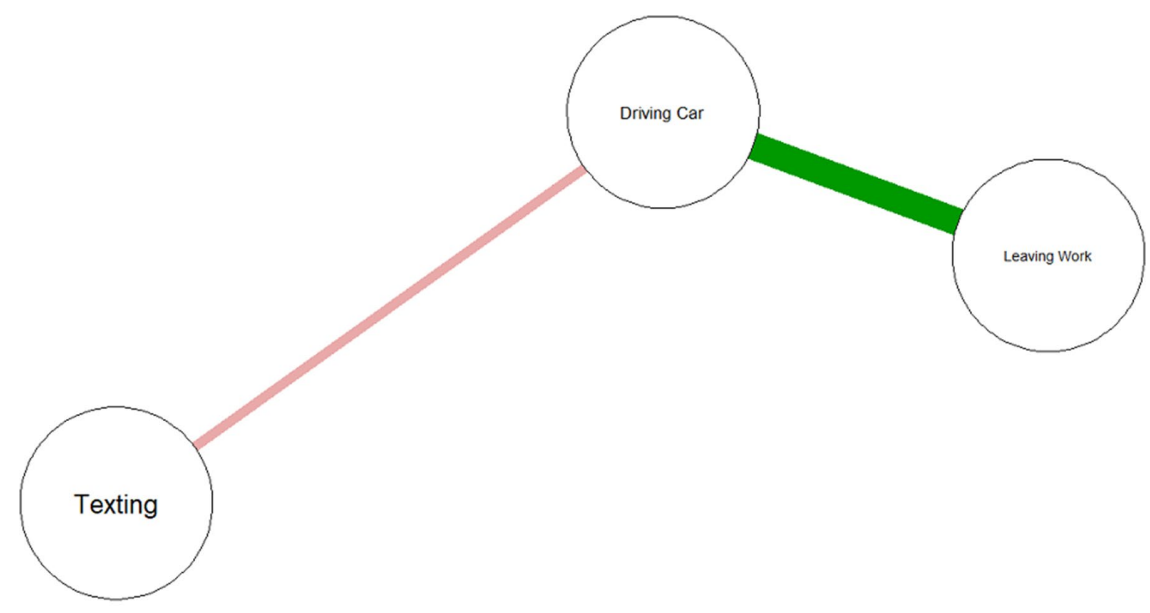

connected by a thick, green line. This indicates a strong, positive association between those two behaviors. In other words, individuals who leave work are also very likely to drive a car-presumably to go home, in this instance. Conversely, a thin, red line connects "Driving Car" and "Texting." This indicates a weak, negative association between those two behaviors. In other words, individuals who drive a car are less likely to also be simultaneously texting, although that association is a weak one (i.e., there remains a sizable fraction of individuals within the sample who will text while driving). Finally, the node "Sleeping" shares no edges with any other nodes, which suggests that that particular behavior is not associated with any of the other behaviors represented in the PCN. Importantly, because the focus of the PCN is on behavioral actions, which are categorical variables, the aforementioned relationships are most accurately described as "associations," rather than correlations, as would be the case for numerical variables.

Similar nomenclature and interpretations can be applied to our own work. Specifically, in the PCN models presented herein, the nodes represent behaviors observed during laboratory sessions for courses that either employ the CURE framework or do not employ the framework. Edges depicted in the PCNs indicate relationships that exist between the behaviors, as was the case in Figure 1. Collectively, we ran three stages of the PCN analysis. First, we analyzed instructor behaviors by running PCNs on CURE

non-CURE sections of the laboratory course, we were furthermore interested in identifying and examining behavioral patterns of association that collectively emerged across all CURE and all non-CURE learning environments. To that end, we constructed a series of partial correlation networks (PCNs) representing instructor and student behaviors observed at the beginning, middle, and end of the semester. Network models are a useful tool for depicting relationships and links between variables in a study, including participant behaviors (Epskamp et al., 2018). Therefore, we posited that PCNs could assist us in uncovering unknown dependencies between student and instructor behaviors in CURE and non-CURE contexts as well as permit us to further compare and contrast behavioral patterns between groups.

In general, PCNs consist of both nodes (i.e., circles) and edges (i.e., connecting lines), the former representing discrete variables (such as behaviors) and the latter the relationships that exist between those variables. As an example, Figure 1 represents a hypothetical PCN in which there are four nodes: 1) Driving Car; 2) Texting; 3) Leaving Work; and 4) Sleeping. In this PCN, the nodes "Driving Car" and "Leaving Work" are and non-CURE instructors at the beginning, middle, and end time points during the semester (with data compiled from two video-recorded sessions comprising each time point). We then analyzed student behaviors by similarly running PCNs on CURE and non-CURE students at the beginning, middle, and end time points during the semester. Finally, we combined the student and instructor behaviors into one PCN for the beginning, middle, and end time points to see how the behaviors of instructors and students may interact. Adopting this approach allowed us to effectively characterize student and instructor behaviors within CURE and non-CURE laboratory contexts, investigate patterns of association between behaviors for each participant subgroup, and perform a descriptive comparison of said patterns between the two aforementioned learning environments. All network analyses were performed in R (R Core Team, 2018) using the following packages: qgraph (Epskamp et al., 2012) and bootnet (Epskamp et al., 2018).

We wish to acknowledge that, while the intent of this section is to provide an overview of PCNs, a more technical description of PCNs-including methods for constructing PCNs and 
assessing their stability — can be found in Appendix 1 in the Supplemental Material. Relatedly, a key that identifies and briefly describes all LOPUS codes depicted on the PCNs can be found in Supplemental Table S1.

Student Motivation, Science Identity, and Perceptions of the Laboratory Experience. The Biology Motivation Questionnaire and Science Identity Scale were administered during the first and 14th weeks of the semester at the beginning of each CURE and non-CURE laboratory session, whereas the Laboratory Course Assessment Survey was administered only in a postsemester format (week 14). Students recorded their responses on a researcher-generated answer form, and all responses were entered manually into SPSS (v. 23; IBM, Armonk, NY) for the purposes of analysis. Multiple regression analyses employing an Akaike information criterion feature selection method (AIC) were performed to determine the extent to which student demographic characteristics, course type (CURE vs. non-CURE), and student and instructor behaviors (typical, interactive, or noninstructive) predicted pre/postsemester shifts in the Biology Motivation Questionnaire and Science Identity Scale constructs as well as end-of-term Laboratory Course Assessment Survey outcomes. Forward, backward, and stepwise selection procedures were used to find best fit and explore higher-order interactions. In the linear regression analyses, we considered models with three-way interaction terms and started with an identical set of predictor variables for each outcome. However, as informed by the PCN analyses and stepwise variable selection, the final models include only the terms that result in a parsimonious fit and, hence, do not contain identical predictor variable sets. Relatedly, we established a cutoff value for all partial correlations described herein using a false discovery rate threshold of $10 \%$ to control for the influence of type I errors on the reported outcomes. R was used to conduct all statistical analyses (R Core Team, 2018). Psychometric analyses indicated a high level of reliability for all scales and instruments administered (Cronbach's $\alpha \geq 0.715$ ).

\section{RESULTS \\ Identification of Instructor and Student Behaviors in CURE and Non-CURE Contexts}

Mann-Whitney $U$-tests were performed to discern similarities and differences in instructor and student behaviors between CURE and non-CURE sections of the introductory cell and molecular biology laboratory course. These analyses indicated that the median amount of time CURE instructors engaged in typical and interactive behaviors was, on average, significantly greater than that of their non-CURE colleagues (Table 4). For instance, CURE instructors spent more time writing on the board (14\%; $U=134.00 ; p<0.001)$ and providing feedback (4\%; $U=164.50 ; p=0.003)$ to students in their sections as well as posing questions $(22 \% ; U=105.00 ; p<0.001)$ and initiating one-on-one interaction with individual students or a group of students (48\%; $U=144.00 ; p=0.003$ ) than did non-CURE instructors.

Similarly, students enrolled in CURE sections engaged in more interactive behaviors, including making predictions (2\%; $U=169.00 ; p=0.004)$, initiating one-on-one interaction with the instructor (26\%; $U=144.00 ; p=0.003)$, and asking the instructor a question with the entire class listening $(3 \% ; U=$
111.00; $p<0.001$ ) than did their non-CURE peers. Conversely, while the majority of typical and noninstructive student behaviors was found to be statistically equivalent between groups, non-CURE participants' median time completing tests/quizzes was found to be significantly greater than that of CURE participants $(6 \%$; $U=47.00 ; p<0.001$; Table 4$)$. This suggests that, within the contexts examined, tests/quizzes were a more routine component of the non-CURE laboratory sections than the CURE laboratory sections-an observation corroborated by review of relevant CURE and non-CURE syllabi for the sections included in this research.

Importantly, although many instructor and student behaviors were found to not be significantly different between groups following Bonferroni correction, we contend that evidence (or lack thereof) of these behaviors has practical implications for student learning and professional growth in laboratory contexts. More specifically, descriptive analysis of these behaviors reveals that the median time CURE participants (both instructors and students) are engaged in interactive behaviors (e.g., whole-class discussion, student interaction between groups, instructors talking to students one-on-one) is commonly greater than that of their non-CURE counterparts. CURE instructors were also observed to engage in a higher median frequency of lecturing than their non-CURE colleagues. Informal conversations with CURE instructors suggest that this is due to a belief that students will be unfamiliar with the foundational subject matter content underlying the CURE (unpublished data). Thus, more formal instruction in such content is necessary to ensure that students are prepared to conduct research in a rigorous and meaningful manner within CURE contexts.

\section{Patterns of Association between Behaviors Differ in CURE versus Non-CURE Contexts}

In an effort to increase the clarity and readability of the PCNs, an a priori decision was made to use the Fruchterman-Reingold algorithm to plot the networks with nodes color-coded by category of behavior, as defined by Velasco et al. (2016). Additional detail regarding this approach can be found in Appendix 1 in the Supplemental Material. With respect to the PCNs depicted below in Figures 2-4, blue nodes indicate instructor and/or student behaviors that are typical, yellow nodes indicate behaviors that are interactive, and pink nodes indicate behaviors that are noninstructive. Sometimes, interactive behaviors can associate with typical or noninstructive behaviors and so on. This is important to note, because some classroom activities (such as making a presentation of research results) may realistically involve any or all of the behavior categories.

\section{Instructor Behaviors}

Global analysis of instructor behaviors reveals that the associations existing between all behavioral categories change across course type (CURE vs. non-CURE) as well as time points during the semester (beginning, middle, end). Importantly, this initial observation suggests that patterns in instructional practices are fluid rather than fixed. Specific analysis of CURE learning environments indicates that, at the beginning of the course, monitoring (M), follow-up/feedback (FUp), and waiting (W) are strongly and positively associated with one another (Figure 2). In other words, CURE instructors who engage in higher levels of monitoring also tend to more routinely provide feedback to 

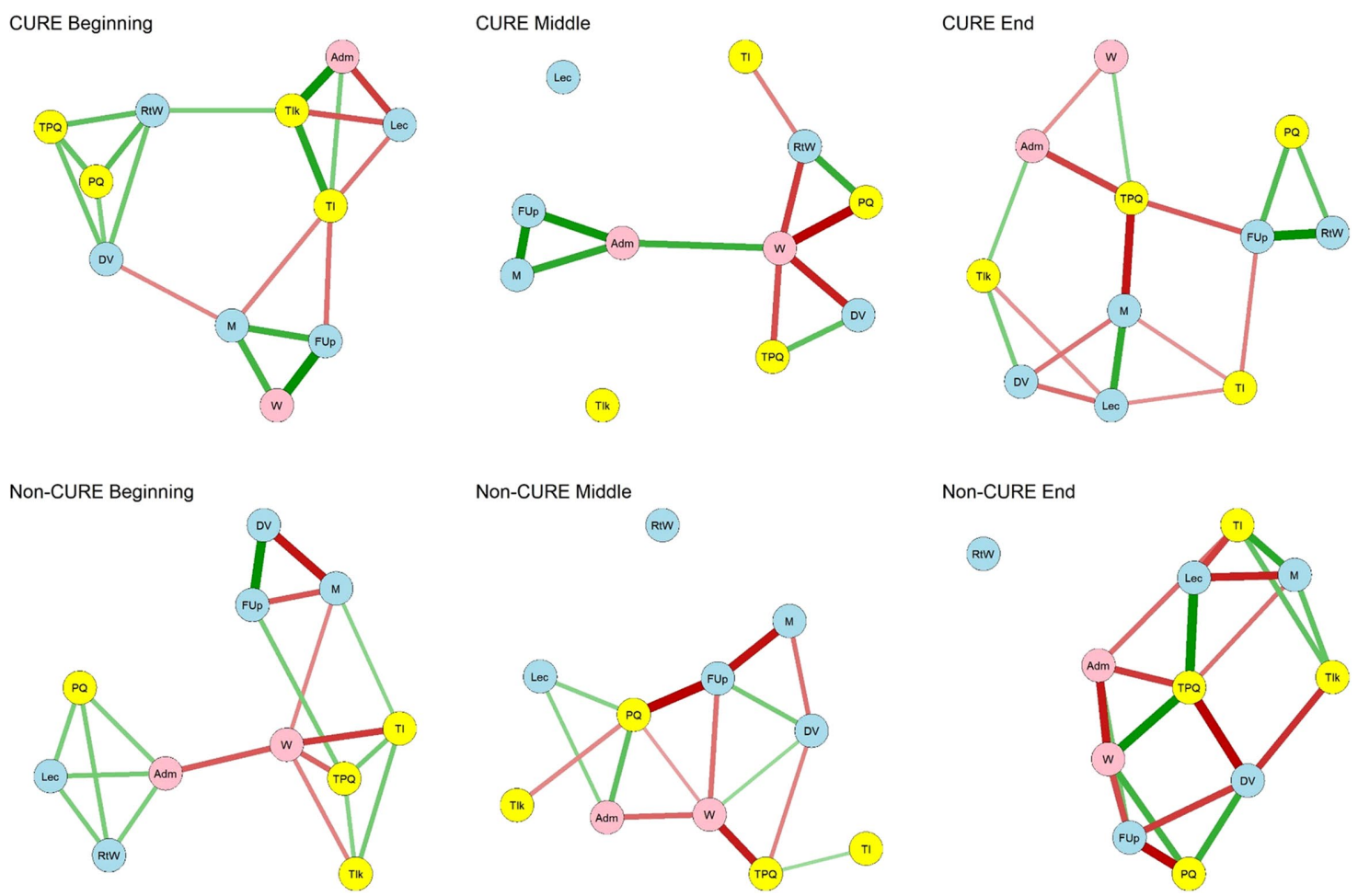

FIGURE 2. PCNs representing associations between instructor behaviors at the beginning, middle, and end of the semester for CURE and non-CURE learning environments. Blue nodes indicate typical behaviors (Lec, RtW, FUp, DV, M); yellow nodes indicate interactive behaviors (PQ, Tlk, TPQ, TI); and pink nodes indicate noninstructive behaviors (Adm, W). Node abbreviations are as described in Table 4.

their students and pause without directly interacting with students. Additionally, the cluster at the top left reflects moderate, positive associations between writing on the board (RtW), demonstrations (DV), posing nonrhetorical lab-related questions (PQ), and posing questions to individual students or a group of students (TPQ). Finally, the top-right cluster, which includes lecturing (Lec), initiating one-on-one interaction with students (TI), talking to students one-on-one (Tlk), and administrative tasks (Adm), shows positive associations between interactive and noninstructive behaviors. However, lecturing (a typical behavior) is negatively associated with the other three behaviors, indicating that CUREs with high levels of lecturing at the start of the semester are associated with low levels of interaction and administrative activities.

With respect to the non-CURE courses, analysis of the upper-right cluster at the beginning of the semester reveals a strong, positive association between conducting demonstrations (DV) and providing follow-up/feedback (FUp). Conversely, moderate to strong, negative associations exist between monitoring (M) and both follow-up/feedback and demonstrations. A second cluster, at the bottom left, reveals moderate, positive associations between lecturing (Lec), writing on the board (RtW), posing questions (PQ), and administrative tasks (Adm). In other words, the latter cluster, for example, indicates that individuals who engage in lecturing are also more likely to write on the board, pose questions, and engage in administrative responsibilities. Practically speaking, a classroom episode encompassing these behaviors might involve the instructor first preparing for class or handing back assignments. Subsequently, he or she might facilitate a short lecture, pausing to write on the board - perhaps to convey content and/or draw a visualization of some sort. Periodically throughout this short lecture, the instructor might pause to ask the students a question about the content displayed on the board. Indeed, our analyses of instructor video data revealed that this was a common sequence of behaviors for some of the non-CURE instructor participants in this study.

Concentrating next on the middle PCNs, and first for the CURE participants, it is noteworthy that waiting (W) is a central node, because it serves as the connection point for three clusters of behaviors. This implies a multiple regression relationship wherein the connected nodes are strong predictors of waiting. Each of the clusters connected to waiting provides insight into associations that are, perhaps, due to an underlying and unobserved variable. Note, also, that some interactive (posing nonrhetorical questions $[\mathrm{PQ}]$, posing questions to individual students or a group of students [TPQ]) and other typical (demonstrations [DV], real-time writing [RtW])—albeit proactive-classroom behaviors are all negatively associated with waiting in the midsemester CURE PCN. This kind of relationship is not replicated in the midsemester non-CURE PCN and is indicative of a wider and perhaps more arbitrary association structure in the non-CURE classes.

With broader regard to the changes the changes observed between the beginning, middle, and end time points for the CURE PCNs, note that the cluster that reflects associations between administrative behaviors, monitoring, and follow-up/ feedback (Adm, M, FUp) and waiting (W) and a second cluster 


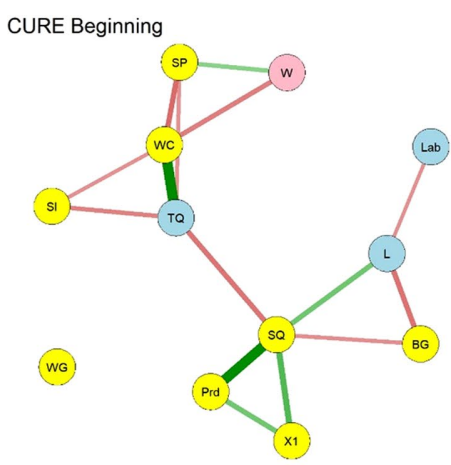

CURE Middle

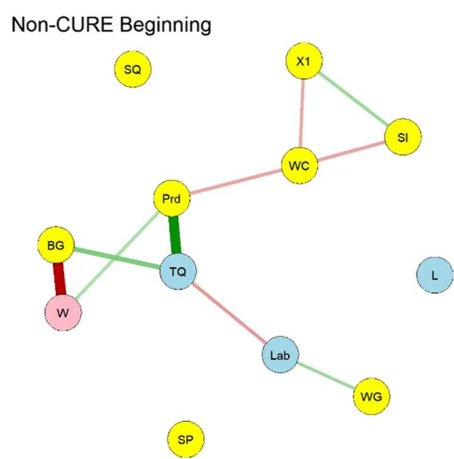

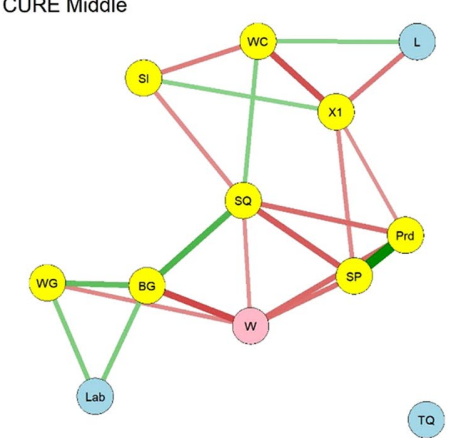

CURE End
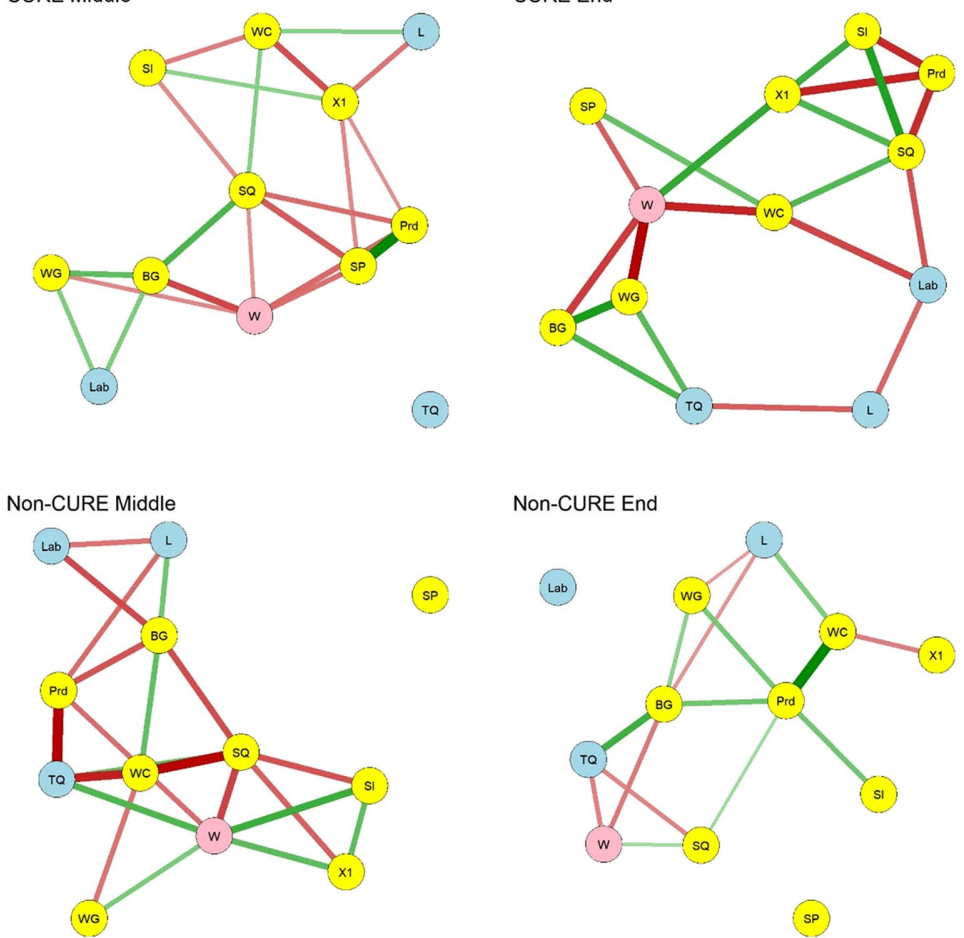

Non-CURE End

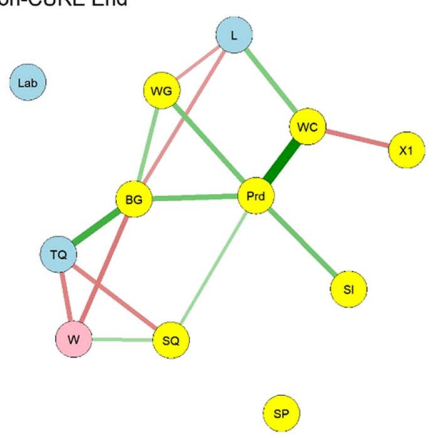

FIGURE 3. PCNs representing associations between student behaviors at the beginning, middle, and end of the semester for CURE and non-CURE learning environments. Blue nodes indicate typical behaviors (L, Lab, TQ); yellow nodes indicate interactive behaviors (SQ, X1, WC, Prd, SP, SI, WG, BG); and pink nodes indicate noninstructive behaviors (W). Node abbreviations are as described in Table 4.

that reflects associations between demonstrations, posing questions to either individuals/groups or the entire class, and realtime writing (DV, TPQ, PQ, RtW) and waiting (W) are not replicated in the beginning and end time points. This lack of replication of the clusters is also repeated for the non-CURE PCNs with the difference that the possible clusters are far less identifiable for non-CURE sections.

\section{Student Behaviors}

To best articulate the behavioral patterns evidenced by students as they were fully engaged in laboratory activities, we made an a priori decision to focus on comparison of CURE and nonCURE students during the middle time point in the semester. By this time, students in CUREs have undergone much of the scaffolding that is integrated into each of the CURE courses to augment their scientific literacy and experimental design skills, as indicated by each of the respective CURE course syllabi. Therefore, the middle time point offers a unique opportunity to explore how CURE students and their respective instructors behave and interact when engaged in the research process. Comparatively, non-CURE students and instructors are engaged in weekly laboratory exercises that are aligned with content presented in the accompanying lecture portion of the course (rather than, for instance, generic exercises that focus on the steps of the scientific method or reading primary literature). Additionally, emphasis on the middle time point for both CURE and non-CURE learning environments affords us the opportunity to focus on formative student-instructor feedback loops while avoiding the diminished frequency of research/laboratory activities and increased frequency of student presentations that are often characteristic of the end of the semester (i.e., the end time point).

For CURE students, waiting (W) was found to have a moderate to strong, negative association with several interactive behaviors, including: 1) asking the instructor a lab-related question with the rest of the class listening (SQ); 2) making predictions (Prd); 3) giving presentations (SP); 4) engaging in within-group interactions (WG); and 5) engaging in between-group interactions (BG; Figure 3). Furthermore, engaging in laboratory exercises (Lab), within-group interaction (WG), and betweengroup interaction (BG) formed a cluster. While difficult to see in the graph, individual components of the cluster that include within- and between-group interactions and completing laboratory exercises (WG, BG, Lab) are negatively associated with waiting (W), similar to the aforementioned interactive behaviors. In other words, CURE students who engage in laboratory activities that promote high levels of within-group and betweengroup student-student interaction as well as other interactive behaviors spend less time waiting during laboratory activities.

This relationship is not replicated for the non-CURE course sections, where the most salient associations are negative and involve behaviors like asking the instructor a question in front of the entire class (SQ), whole-class discussion (WC), taking tests or quizzes (TQ), and making predictions (Prd). It is interesting that these negative associations indicate that non-CURE students who spend greater amounts of time taking tests/quizzes generally display fewer interactive behaviors. These associations are not observed for the CURE classrooms and may suggest that the CURE courses, in general, support interactive behavior if waiting is minimized, while the non-CURE courses 

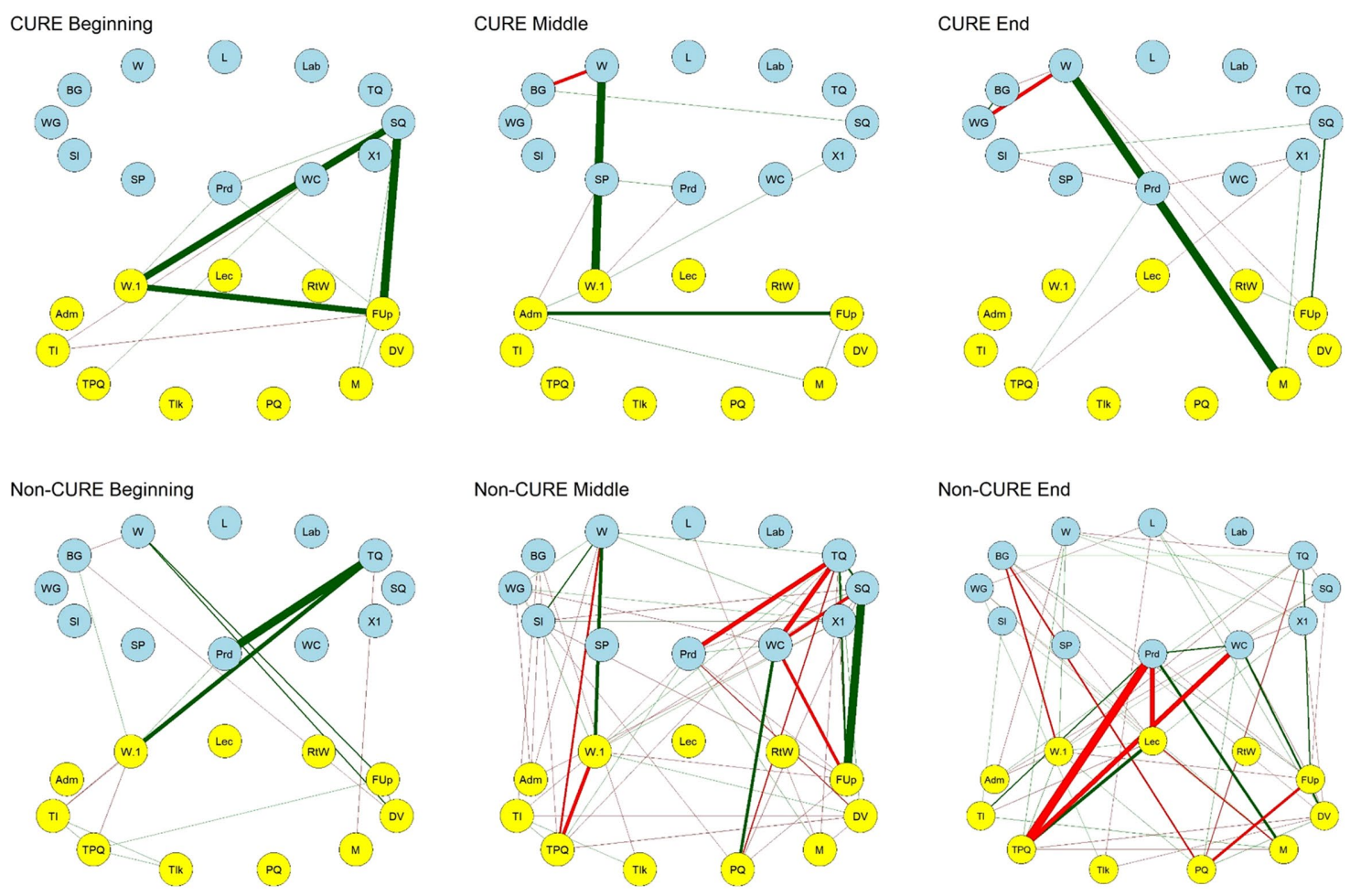

FIGURE 4. PCNs representing associations between both instructor and student behaviors at the beginning, middle, and end of the semester for CURE and non-CURE learning environments. Blue nodes indicate student behaviors, whereas yellow nodes indicate instructor behaviors. Node abbreviations are as described in Table 4 and Figures 2 and 3, with the exception that "W.1" is used to indicate instructor waiting so as not to confuse that variable with student waiting (W).

can achieve a similar outcome by potentially reducing the frequency of tests/quizzes that are administered.

\section{Aggregated Instructor and Student Behaviors}

For the combined PCNs that involve both instructor and student behaviors, the student behaviors are in blue and the instructor behaviors are in yellow. As previously indicated, a cutoff value for the partial correlations described here was established using a false discovery rate controlled at $10 \%$ to reduce the likelihood of potential false-positive results. When interpreting the PCNs, it is likewise important to note that some edges may cross under unrelated nodes, as the two-dimensional image is modeled in three-dimensional space. For example, in the middle CURE PCN graph (Figure 4), the thick, green edge connecting waiting for the student and waiting for the instructor (W and W.1, respectively) passes behind the student behavior of giving a presentation (SP). However, the student behavior of giving a presentation is not connected to either student waiting or instructor waiting behaviors.

Overall, the most salient association observed between instructors and students in CURE courses at the beginning of the term was a positive association between students posing questions to the instructor (SQ), the instructor waiting (W.1), and the instructor providing follow-up/feedback (FUp). Further analyses indicate that student waiting (W) was associated with instructor waiting (W.1) and monitoring (M) during the mid-semester and end-of-semester time points, respectively (Figure 4).

Comparatively, in non-CURE contexts, analysis of the PCN for the beginning of the course reveals strong, positive associ- ations between students taking tests or quizzes (TQ), students making predictions (Prd), and the instructor waiting (W.1). During the middle time point, the most salient association occurs between asking the instructor a question (SQ) and the instructor following up on an activity (FUp). This is a positive association, which implies that, in non-CURE courses where students frequently ask the instructor a question, there are also many instances of instructor follow-up behavior. Finally, the PCN representing the end-of-semester time point reveals a strong, negative association between the instructor posing a question to individual students or group of students (TPQ) and students making predictions (Prd). It is interesting to note that posing questions to individuals or groups of students (TPQ) is positively associated with lecturing (Lec), whereas making predictions (Prd) is negatively associated with lecturing (Lec), suggesting that instructors who employ a greater amount of call-and-response lecture in their sections likewise engage students in lower levels of making predictions about the outcome of the experiments that they are performing.

\section{Impacts of Student and Instructor Behaviors on Noncognitive Student Outcomes}

While several studies have examined the impact of CURE curricula on student cognition and affect (e.g., Harrison et al., 2011; Hanauer and Dolan, 2014; Jordan et al., 2014; Brownell et al., 2015; Olimpo et al., 2016; Rodenbusch et al., 2016; Sarmah et al., 2016), no studies, to the best of our knowledge, have explored the association between student and instructor behaviors and noncognitive student outcomes in 
TABLE 5. Regression analyses examining the impact of demographic characteristics, instructor behaviors, and student behaviors on noncognitive student outcomes

\begin{tabular}{|c|c|c|}
\hline Construct & 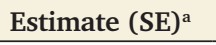 & $p$ value \\
\hline \multicolumn{3}{|l|}{ Collaboration } \\
\hline Student interactive behaviors (SIB) & $0.066(0.045)$ & 0.144 \\
\hline Instructor interactive behaviors (IIB) & $0.036(0.013)$ & 0.005 \\
\hline Course type ${ }^{b}$ & $4.966(3.601)$ & 0.171 \\
\hline Course type*SIB & $-0.152(0.060)$ & 0.012 \\
\hline \multicolumn{3}{|l|}{ Discovery } \\
\hline Instructor interactive behaviors (IIB) & $0.019(0.013)$ & 0.142 \\
\hline Course type & $-4.049(1.152)$ & $<0.001$ \\
\hline \multicolumn{3}{|l|}{ Iteration } \\
\hline Student interactive behaviors (SIB) & $-0.129(0.143)$ & 0.369 \\
\hline Instructor typical behaviors (ITB) & $-0.240(0.151)$ & 0.115 \\
\hline SIB*ITB & $0.003(0.002)$ & 0.129 \\
\hline \multicolumn{3}{|l|}{ Intrinsic motivation } \\
\hline Student interactive behaviors (SIB) & $-0.063(0.045)$ & 0.166 \\
\hline Instructor interactive behaviors (IIB) & $-0.033(0.018)$ & 0.073 \\
\hline SIB*IIB & $0.001(0.0003)$ & 0.073 \\
\hline \multicolumn{3}{|l|}{ Career motivation } \\
\hline Course type & $1.594(0.687)$ & 0.022 \\
\hline \multicolumn{3}{|l|}{ Self-determination } \\
\hline Instructor interactive behaviors (IIB) & $0.015(0.007)$ & 0.034 \\
\hline \multicolumn{3}{|l|}{ Self-efficacy } \\
\hline Instructor typical behaviors (ITB) & $0.342(0.144)$ & 0.019 \\
\hline Instructor interactive behaviors (IIB) & $0.161(0.071)$ & 0.025 \\
\hline ITB*IIB & $-0.002(0.001)$ & 0.026 \\
\hline \multicolumn{3}{|l|}{ Science identity } \\
\hline Course type & $6.602(3.220)$ & 0.043 \\
\hline
\end{tabular}

${ }^{a}$ Estimates are reported as unstandardized $\beta$ values; $\mathrm{SE}=$ standard error.

${ }^{\mathrm{b} C}$ Course type represents CURE vs. non-CURE status of the laboratory section.

such environments. Consistent with Cohen and Ball's (1999) conceptual framework for instructional capacity, however, we contend that exploration of the intersection between students, instructors, and instructional materials (i.e., course type) is warranted in order to fully realize and understand the relationships between these factors that exist across diverse laboratory environments. Thus, through use of a series of multiple linear regressions employing an information criterion feature selection method (AIC), we sought to identify the extent to which student demographic characteristics, PCN-informed aggregate student and instructor behaviors (i.e., typical, interactive, noninstructive), and course type (CURE vs. non-CURE) predicted the following student outputs: pre/postsemester shifts in 1) intrinsic motivation, 2) career motivation, 3) self-determination, 4) self-efficacy, and 5) science identity development as well as 6) perceived collaboration within the course, 7) perceived opportunities to make relevant scientific discoveries within the course, and 8) perceived iteration within the course. Responses to the Biology Motivation Questionnaire, Science Identity Scale, and the Laboratory Course Assessment Survey were used to assess outputs $1-4,5$, and $6-8$, respectively. Note than an a posteriori decision was made to exclude grade motivation from our analyses, as this variable was not posited to be linked to course-specific activities or individual behaviors (Auchincloss et al., 2014; Olimpo et al., 2016). Results are presented in Table 5.

Collectively, these data suggest that participation in a CURE is a positive predictor of science identity development, career motivation, and one's perceived ability to make relevant scientific discoveries ( $p \leq 0.043$ for all analyses). Closer examination of instructor and student behaviors within both CURE and nonCURE contexts demonstrates that interactive instructor behaviors positively predict collaboration and self-determination (Table 5). Additionally, a significant interaction effect is observed between typical and interactive instructor behaviors and their joint influence on shifts in students' self-efficacy. Specifically, the effect of interactive instructor behaviors on self-efficacy depends on the levels of typical instructor behaviors, because students in courses with higher levels of interactive instructor behaviors (and lower levels of typical instructor behaviors) have greater pre/postsemester shifts in self-efficacy.

Our analyses further revealed a significant interaction effect between course type and student interactive behaviors and their joint influence on students' perceptions of collaboration within their respective laboratory environments. Specifically, when predicting collaborative activities, the negative interaction slope between course type and student interactive behaviors indicates that an increase in student interactive behaviors positively increases students' perceptions of collaboration in CURE sections but decreases students' perceptions of collaborative work in non-CURE sections. Perhaps this effect is observed due to the interactive behaviors being oriented toward different purposes in CURE and non-CURE courses and could be examined further by a study documenting the nature and quality of student interactive behaviors.

\section{DISCUSSION}

CUREs are designed to provide all students with access to authentic scientific opportunities (Bangera and Brownell, 2014). Increasing evidence demonstrates that CUREs positively impact students' perceptions of the research process, their self-efficacy and identity as scientists, and their persistence in STEM (Russell and Weaver, 2011; Szteinberg and Weaver, 2013; Corwin et al., 2015; Hanauer et al., 2017). Yet, few studies have explored the contextual features of CURE learning environments that mediate such outcomes as well as, importantly, how non-CURE classrooms comparatively attend to those same factors and outcomes.

In this article, we sought to address these concerns through examination of instructor and student behaviors within both CURE and non-CURE introductory cell and molecular biology laboratory contexts. In keeping with the conceptual framework guiding this study, we furthermore investigated the relationship between these behaviors and noncognitive student outcomes in the contexts described. Collectively, our analyses indicate that: 1) CURE instructors and students use interactive behaviors more frequently than their non-CURE counterparts; 2) patterns of association between typical and interactive behaviors differ for both instructors and students when comparing CURE and non-CURE contexts; and 3) course type (CURE vs. non-CURE) and both student and instructor interactive behaviors predict a diversity of noncognitive student outcomes ranging from science identity development to career motivation. 
Instructors of CUREs frequently engaged students in open dialogue during class time, whether through one-on-one interaction, posing questions to an individual student or group of students, and/or providing feedback on student work ( $\geq 4 \%$ median time in all categories across the semester). CURE instructors likewise spent more than $25 \%$ of their time lecturing to students in the course. Informal, post-hoc conversations with CURE instructors indicated that the latter observation was likely due to a belief that students required foundational knowledge in the field of study underlying the CURE in order to successfully engage in the research process (unpublished data). In contrast, non-CURE instructors monitored the class/student groups and engaged in administrative tasks to a greater extent than their CURE colleagues (see Table 4).

We acknowledge that this study is quasi-experimental in nature, and thus we did not specify which pedagogical techniques instructors should employ or at what frequency. Therefore, care must be taken not to overgeneralize the betweengroup similarities and differences in behavioral actions evidenced by CURE and non-CURE educators when interpreting our findings. However, in concert with results reported by Velasco et al. (2016), our data suggest that CURE instructors, in general, adopt a "guide-on-the-side" instructional style, characterized by high levels of one-on-one interaction with students. In contrast, non-CURE instructors exhibited behaviors that were more indicative of the "observer" style of teaching, in which monitoring of students as they complete experiments occurs at high frequency. Data presented in Table 4 corroborate these profiles, with CURE instructors posing questions to individual students/groups of students (TPQ) and initiating oneon-one interaction with individual students/groups of students (TI) at a significantly greater median frequency than their nonCURE counterparts. Conversely, non-CURE instructors were found to monitor student groups (M) more often than their peers facilitating CUREs.

In considering the abovementioned instructor designations more broadly, it is critical to note that within-group variations in behavior were likewise observed among individual instructors in both CURE and non-CURE contexts. In other words, it cannot be assumed that all educators who facilitate a CURE or all instructors who facilitate non-CURE coursework will adopt identical instructional styles solely by virtue of course type. A posteriori Kruskal-Wallis test comparisons confirmed this observation (see Supplemental Table S2). While these data likely come as no surprise, given the extensive amount of previously published evidence regarding pedagogical practices in biology lecture and laboratory environments (e.g., DebBurmen, 2002; Freeman et al., 2014; Stains et al., 2015, 2018; Cleveland et al., 2017), we believe that the similarities and differences in instructor behaviors emergent from our own analyses are noteworthy, given that the educational backgrounds and pedagogical training received by instructors who participated in this research were relatively equivalent. Furthermore, while several studies have focused on the reasons faculty facilitate laboratory coursework (e.g., Shortlidge et al., 2015), we strongly advocate for future work that explores the factors impacting graduate teaching assistants' pedagogical practices and motivations for teaching, particularly in CUREs (e.g., see Heim and Holt, 2019). Insights drawn from such studies will inevitably serve to advance our understanding of how to best prepare instructors to effectively promote student learning, affect, and success in CURE environments.

In focusing on student participants, our analyses demonstrate that individuals within CUREs engaged more frequently in making predictions and interacting with the instructor than did their non-CURE peers. Conversely, non-CURE students spent more time taking quizzes/tests than did CURE students ( $6 \%$ median time vs. $0 \%$ median time, respectively). Review of course syllabi confirms that quizzes served as the primary mode of summative assessment in the non-CURE sections, whereas variable forms of summative assessment were used in the CURE courses that we surveyed. This pattern of evaluation is well-documented in the literature and reifies the notion that instructors in CURE and non-CURE contexts may differ in their beliefs about what is valuable in terms of student learning objectives and how to best measure whether or not those objectives have been achieved (Clough, 2002).

Beyond the scope of instructional materials (e.g., laboratory exercises, assessment), our findings reveal distinct, positive relationships between instructor interactive behaviors (e.g., initiating one-on-one interactions with students) and students' development of self-efficacy, self-determination, and perceptions of collaboration in the laboratory environment. These data and other complementary PCN analyses conducted suggest that the behaviors evidenced by the instructor and the ways in which the instructor gives life to the laboratory content directly impact how students engage with that content (akin to the findings of Hofstein and Lunetta, 2004; Apedoe et al., 2006). These findings mirror those of Polman (2000), which suggest that science instructors must be interactive and involved in constant and productive discourse with their students in order to facilitate growth in students' conceptual understanding of science content. Moreover, research in the discipline indicates that lack of instructor buy-in to the pedagogical techniques that they are encouraged to incorporate into their laboratories can impact both their interactions with students (e.g., an instructor finds whole-class discussion to be time-consuming) and interactions between students (e.g., an instructor feels between-group collaboration is too disruptive), resulting in overall inhibition of interactions within the laboratory (Goertzen et al., 2009). Consequently, we strongly encourage laboratory instructors (CURE or otherwise) to purposefully consider the amount of time they spend engaging with students and suggest that periods of interaction, questions, and single-group/whole-class discussion be integrated into the course to ensure that instructor-student interactions occur and that those interactions effectively promote students' academic and professional development (O'Neal et al., 2007).

It is important to acknowledge, of course, that the nature of such interactions is likely to be highly dynamic at any given point in time. PCN analyses reported in this article reveal, for instance, that instructor and student behaviors observed over the duration of a single semester are fluid (rather than fixed) and reflect a complex interplay between typical, interactive, and noninstructive moves. Notably, CURE instructors frequently engaged in associated patterns of real-time writing (RtW) and posing nonrhetorical questions (PQ) to students within their course sections as well as associated patterns of monitoring (M) and following up (FUp) on student progress. Conversely, similar clustering of behaviors was not observed as consistently for 
non-CURE instructors, and the clusters that did emerge were found to shift over time (Figure 2).

PCN data derived from CURE student behaviors, in turn, suggest a progression wherein scholars spend the earlier part of the semester posing questions to the instructor (X1, SQ), which is associated with making predictions about the experiments that they are performing. As the semester progresses and students immerse themselves in the research process, they are observed to interact with individuals both within and outside their own laboratory teams (note the WG, BG, Lab cluster in the "CURE Middle" PCN in Figure 3). They likewise continue to make predictions, which is now strongly and positively associated with students giving presentations. Presumably, and consistent with qualitative observation of collected video data, this is reflective of students generating new ideas about a research project following opportunities to share "progress updates" via both formal and informal oral presentations. Positive, strong associations between interactive behaviors are found toward the end of the semester, when students are seen to continue to interact both with their peers (note the BG, WG, TQ cluster) and the instructor (note the SI, $\mathrm{X} 1$, SQ cluster).

These same patterns are not observed for students enrolled in non-CURE sections, where, as in the middle PCN, most associations are negative and imply that one interactive behavior is less frequently done in conjunction with another interactive behavior. Likewise, interpretation of the middle PCN reveals that, as students engage in laboratory work (Lab), this is often done with limited interaction between laboratory groups (BG) and, potentially, even limited interaction within groups (note the lack of association between Lab and WG in Figure 3).

Collectively, we contend that the PCN outcomes described herein reflect the differences in course structure inherent of CURE versus non-CURE learning environments. In concert with Auchincloss et al.'s (2014) framework, the intent of CUREs is to immerse students in the process of doing science, from the initial identification or development of a novel question through to dissemination of their findings to the broader community. Accordingly, this framework promotes a view of "doing" science as one that is continuous and iterative, in which scientists work to rigorously explore phenomena in their field by revisiting methods, results, analyses, and even the initial research questions themselves. Indeed, in his study of how students engaged in the scientific process as they formulated and conducted single-course-session research projects, Harwood (2004) notes that participants often revisited certain aspects of their experimental "plans" after having initially completed that component of the plan, such as redefining the research question after reading new literature in the discipline.

Comparatively, traditional laboratory exercises often provide little continuity with respect to projects and content delivered throughout the semester, instead favoring the mindset that students should be exposed to a wide variety of scientific techniques and concepts in parallel with the associated lecture course in which they are enrolled (Domin, 1999; Katchevich et al., 2013). It is, perhaps, therefore unsurprising that we find inconsistent patterns of association between student and instructor behaviors (both exclusively and considered in aggregate) for non-CURE participants in the current study.
Uniquely, our study contributes to the growing effort to explore the relationship between instructor and student behaviors and noncognitive student outcomes in laboratory contexts (e.g., Velasco et al., 2016) and provides new insight into potential relationships that might exist in CUREs, specifically. Notably, course type (i.e., enrollment in a CURE) was observed to positively impact students' science identity development, career motivation, and perceived ability to make novel scientific discoveries. These results are consistent with prior literature in the field. In their analysis of student outcomes following participation in the Tigriopus CURE, Olimpo and colleagues (2016) demonstrated, for instance, that students who participated in the CURE exhibited more positive pre/postsemester shifts in their intrinsic motivation, career motivation, self-determination, and self-efficacy than did a matched comparison group composed of students enrolled in the traditional laboratory experience. Relatedly, the work of Corwin et al. (2015, 2018) reveals that students who engage in CUREs-as compared with students in non-CURE laboratories-report higher levels of affect associated with perceived discovery of information that may be relevant and of interest to the scientific community.

Additionally, interactive instructor behaviors were found to be a positive predictor of collaboration and self-determination, independent of course type. Such behaviors likewise mediated student shifts in self-efficacy, with an interaction effect observed between interactive and typical instructor behavioral actions. In other words, increases in students' self-efficacy are related to increased use of interactive instructor behaviors; however, the extent of this effect can vary depending on the degree to which the instructor likewise engages in typical behavioral actions (e.g., augmentation in student self-efficacy can be reduced if the instructor makes extensive use of typical behaviors, even if they simultaneously use interactive behaviors). This finding is consistent with previous studies in the field (Wubbels and Brekelmans, 2005; Cornelius-White, 2007; Seidel and Tanner, 2013). While discussions pertaining to instructional practices (and their relationship to student learning and professional development) may be minimized at the course or departmental level due to the pressing nature of more immediate and tangible needs (e.g., resources, classroom management; Loughran, 2013), we contend that conversations around pedagogy need to be more explicit, particularly in the training of graduate teaching assistant instructors and especially in the context of CUREs. To achieve this goal, we furthermore advocate for the modification of existent, integrated frameworks for CURE development and linked student outcomes to include contextual features (e.g., participant behaviors) that may influence those processes and products. For instance, Auchincloss and colleagues' (2014) seminal CURE framework could be expanded to denote potential relationships between student and instructor behaviors and short-, medium-, and long-term student outcomes.

Several limitations are inherent to this study. The CURE and non-CURE laboratory sections of the course were taught at different times of the day, for different amounts of time, and with different instructors and numbers of students per section. It is therefore possible that the observed behaviors and noncognitive student outcomes measured were due to these differences. To control for differences related to when the courses were offered, we created exact or near-exact temporal matches between CURE 
sections and non-CURE sections (i.e., CURE and non-CURE sections offered on the same day at approximately the same time were matched). While the prescribed length of class sessions was beyond our control and while they effectively act as a proxy for course type, within-group comparisons of instructor and student behaviors in both CURE and non-CURE contexts revealed significant differences in instructional styles between instructors as well as the actions undertaken by students in their courses. In other words, if class length was a causal determinant of instructor/student behaviors, we might expect instructors to teach in a relatively homogeneous manner and students to behave similarly within a given course type, which was not the case here. Finally, in an effort to reduce confounding due to student and instructor demographic characteristics, we both identified and attempted to account for these factors in our analyses. We recommend, however, that future research explore the connections between student and instructor characteristics, classroom behaviors, and outcomes on a national scale in an effort to create a truly representative account of the interaction between each of these factors in CURE and other laboratory environments.

In conclusion, our data indicate that the collective behaviors evidenced by instructors and students in CURE and non-CURE contexts often favor more interactive and noninstructive actions, respectively. Furthermore, visualization methods, such as the construction of PCNs, can assist in identifying behavioral trends or patterns, including similarities and differences between groups of individuals across diverse course types (similar to the cluster analyses in Velasco et al., 2016). Finally, and perhaps most critically, our findings serve to emphasize the importance of the purposeful consideration of the pedagogical strategies that instructors elect to employ when considering noncognitive student outcomes in laboratory classrooms. As instructional approaches in laboratory courses continue to evolve, careful attention to these aforementioned factors will be critical in ensuring that we best prepare students to be lifelong STEM learners and scholars.

\section{ACKNOWLEDGMENTS}

We thank Mr. Dimuthu Fernando and Ms. Denise Borja for their assistance with data collection, collation, and analysis. Research reported in this publication was supported, in part, by National Institute of General Medical Sciences/National Institutes of Health awards RL5GM118969, TL4GM118971, and UL1GM118970.

\section{REFERENCES}

American Association for the Advancement of Science. (2011). Vision and change in undergraduate biology education: A call to action. Washington, DC.

Apedoe, X. S., Walker, S. E., \& Reeves, T. C. (2006). Integrating inquiry-based learning into undergraduate geology. Journal of Geoscience Education 54(3), 414-421.

Auchincloss, L. C., Laursen, S. L., Branchaw, J. L., Eagan, K., Graham, M., Hanauer, D. I., ... \& Dolan, E. L. (2014). Assessment of course-based undergraduate research experiences: A meeting report. CBE-Life Sciences Education, 13(1), 29-40

Bangera, G., \& Brownell, S. E. (2014). Course-based undergraduate research experiences can make scientific research more inclusive. CBE-Life Sciences Education, 13(4), 602-606.

Bond-Robinson, J., \& Rodriques, R. A. B. (2006). Catalyzing graduate teaching assistants' laboratory teaching through design research. Journal of Chemical Education, 83(2), 313
Brownell, S. E., Hekmat-Scafe, D. S., Singla, V., Seawell, P. C., Imam, J. F. C., Eddy, S. L., ... \& Cyert, M. S. (2015). A high-enrollment course-based undergraduate research experience improves student conceptions of scientific thinking and ability to interpret data. CBE-Life Sciences Education, 14(2), ar21.

Brownell, S. E., Kloser, M. J., Fukami, T., \& Shavelson, R. (2012). Undergraduate biology lab courses: Comparing the impact of traditionally based "cookbook" and authentic research-based courses on student lab experiences. Journal of College Science Teaching, 41(4), 36-45.

Cleveland, L. M., Olimpo, J. T., \& DeChenne-Peters, S. E. (2017). Investigating the relationship between instructors' use of active-learning strategies and students' conceptual understanding and affective changes in introductory biology: A comparison of two active-learning environments. CBE-Life Sciences Education, 16(2), ar19

Clough, M. P. (2002). Using the laboratory to enhance student learning. In Bybee, R. (Ed.), Learning science and the science of learning (pp. 85-94). Arlington, VA: NSTA Press.

Cohen, D. K., \& Ball, D. L. (1999). Instruction, capacity, and improvement (CPRE Research Report Series RR-43). Philadelphia, PA: Consortium for Policy Research in Education, University of Pennsylvania Graduate School of Education.

Cornelius-White, J. (2007). Learner-centered teacher-student relationships are effective: A meta-analysis. Review of Educational Research, 77(1), 113-143.

Corwin, L. A., Runyon, C. R., Ghanem, E., Sandy, M., Clark, G., Palmer, G. C., ... \& Dolan, E. L. (2018). Effects of discovery, iteration, and collaboration in laboratory courses on undergraduates' research career intentions fully mediated by student ownership. CBE-Life Sciences Education, 17(2), $\operatorname{ar} 20$.

Corwin, L. A., Runyon, C., Robinson, A., \& Dolan, E. L. (2015). The laboratory course assessment survey: A tool to measure three dimensions of research-course design. CBE-Life Sciences Education, 14(4), ar37.

DebBurmen, S. K. (2002). Learning how scientists work: Experiential research projects to promote cell biology learning and scientific process skills. Cell Biology Education, 1(4), 154-172.

DeChenne, S. E., Enochs, L. G., \& Needham, M. (2012). Science, technology, engineering, and mathematics graduate teaching assistants' teaching self-efficacy. Journal of the Scholarship of Teaching and Learning, 12(4) 102-123.

Domin, D. S. (1999). A review of laboratory instruction styles. Journal of Chemistry Education, 76(4), 543.

Epskamp, S., Borsboom, D., \& Fried, E. I. (2018). Estimating psychological networks and their accuracy: A tutorial paper. Behavior Research Methods, 50(1), 195-212.

Epskamp, S., Cramer, A. O., Waldorp, L. J., Schmittmann, V. D., \& Borsboom D. (2012). qgraph: Network visualizations of relationships in psychometric data. Journal of Statistical Software, 48(4), 1-18.

Estrada, M., Burnett, M., Campbell, A. G., Campbell, P. B., Denetclaw, W. F. Gutiérrez, C. G., ... \& Zavala, M. (2016). Improving underrepresented minority student persistence in STEM. CBE-Life Sciences Education, 15(3), es5.

Estrada, M., Woodcock, A., Hernandez, P. R., \& Schultz, P. W. (2011). Toward a model of social influence that explains minority student integration into the scientific community. Journal of Educational Psychology, 103(1), $206-222$.

Fay, M. E., Grove, N. P., Towns, M. H., \& Bretz, S. L. (2007). A rubric to characterize inquiry in the undergraduate chemistry laboratory. Chemistry Education Research and Practice, 8(2), 212-219.

Freeman, S., Eddy, S. L., McDonough, M., Smith, M. K., Okoroafor, N., Jordt, H., \& Wenderoth, M. P. (2014). Active learning increases student performance in science, engineering, and mathematics. Proceedings of the National Academy of Sciences USA, 111(23), 8410-8415.

Fuchs, J., Kouyate, A., Kroboth, L., \& McFarland, W. (2016). Growing the pipeline of diverse HIV investigators: The impact of mentored research experiences to engage underrepresented minority students. AIDS and Behavior, 20(2), 249-257.

Galloway, K. R., Malakpa, Z., \& Bretz, S. L. (2016). Investigating affective experiences in the undergraduate chemistry laboratory: Students' perceptions 
of control and responsibility. Journal of Chemical Education, 93(2), $227-$ 238.

Gasper, B. J., \& Gardner, S. M. (2013). Engaging students in authentic microbiology research in an introductory biology laboratory course is correlated with gains in student understanding of the nature of authentic research and critical thinking. Journal of Microbiology \& Biology Education, 14(1), 25.

Germann, P. J., Haskins, S., \& Auls, S. (1996). Analysis of nine high school biology laboratory manuals: Promoting scientific inquiry. Journal of Research in Science Teaching, 33(5), 475-499.

Glynn, S. M., Brickman, P., Armstrong, N., \& Taasoobshirazi, G. (2011). Science Motivation Questionnaire II: Validation with science majors and nonscience majors. Journal of Research in Science Teaching, 48(10), 11591176 .

Goertzen, R. M., Scherr, R. E., \& Elby, A. (2009). Accounting for tutorial teaching assistants' buy-in to reform instruction. Physical Review Special Topics-Physics Education Research, 5(2), 020109.

Gonzalez, H. (2019). Topics in the Study of Life Laboratory Manual. Plymouth, MI: Hayden-McNeil.

Hanauer, D. I., \& Dolan, E. L. (2014). The Project Ownership Survey: Measuring differences in scientific inquiry experiences. CBE-Life Sciences Education, 13(1), 149-158

Hanauer, D. I., Graham, M. J., Betancur, L., Bobrownicki, A., Cresawn, S. G., Garlena, R. A., ... \& Hatfull, G. F. (2017). An inclusive research education community (iREC): Impact of the SEA-PHAGES program on research outcomes and student learning. Proceedings of the National Academy of Sciences USA, 114(51), 13531-13536.

Harrison, M., Dunbar, D., Ratmansky, L., Boyd, K., \& Lopatto, D. (2011). Classroom-based science research at the introductory level: Changes in career choices and attitude. CBE-Life Sciences Education, 10(3), 279-286.

Harwood, W. S. (2004). A new model for inquiry: Is the scientific method dead? Journal of College Science Teaching, 33(7), 29-33.

Heim, A., \& Holt, E. (2019). Benefits and challenges of instructing introductory biology course-based undergraduate research experiences (CUREs) as perceived by graduate teaching assistants. CBE-Life Sciences Education, 18(3), ar43.

Hernandez, P. R., Schultz, P., Estrada, M., Woodcock, A., \& Chance, R. C. (2013). Sustaining optimal motivation: A longitudinal analysis of interventions to broaden participation of underrepresented students in STEM. Journal of Educational Psychology, 105(1), 89.

Hernandez, P. R., Woodcock, A., Estrada, M., \& Schultz, P. W. (2018). Undergraduate research experiences broaden diversity in the scientific workforce. BioScience, 68(3), 204-211.

Hofstein, A., \& Lunetta, V. N. (2004). The laboratory in science education: Foundations for the twenty-first century. Science Education, 88(1), 28-54

Jordan, T. C., Burnett, S. H., Carson, S., Caruso, S. M., Clase, K., DeJong, R. J., .. \& Hatfull, G. F. (2014). A broadly implementable research course in phage discovery and genomics for first-year undergraduate students. MBio, 5(1), e01051-13.

Katchevich, D., Hofstein, A., \& Mamlok-Naaman, R. (2013). Argumentation in the chemistry laboratory: Inquiry and confirmatory experiments. Research in Science Education, 43(1), 317-345

Loughran, J. (2013). Developing a pedagogy of teacher education: Under standing teaching and learning about teaching. New York: Routledge.

National Academies of Sciences, Engineering, and Medicine. (2017). Undergraduate research experiences for STEM students: Successes, challenges, and opportunities. Washington, DC: National Academies Press.

National Research Council. (2003). BIO2010: Transforming undergraduate education for future research biologists. Washington, DC: National Academies Press.

National Science Foundation. (2003). Exploring the concept of undergraduate research centers: A report on the NSF workshop. Arlington, VA.

Okebukola, P. A. (1984). In search of a more effective interaction pattern in biology laboratories. Journal of Biological Education, 18(4), 305-308.

Olimpo, J. T., Apodaca, J., Hernandez, A., \& Paat, Y.-F. (2019). Disease and the environment: A health disparities CURE incorporating civic engagement education. Science Education and Civic Engagement: An International Journal. Retrieved January 1, 2019, from https://new.seceij.net/articletype/ disease-and-the-environment

Olimpo, J. T., Fisher, G. R., \& DeChenne-Peters, S. E. (2016). Development and evaluation of the Tigriopus course-based undergraduate research experience: Impacts on students' content knowledge, attitudes, and motivation in a majors introductory biology course. CBE-Life Sciences Education, 15(4), ar72.

O'Neal, C., Wright, M., Cook, C., Perorazio, T., \& Purkiss, J. (2007). The impact of teaching assistants on student retention in the sciences: Lessons for TA training. Journal of College Science Teaching, 36(5), 24-29.

Polman, J. L. (2000). Designing project-based science: Connecting learners through guided inquiry. Ways of knowing in science series. Williston, VT: Teachers College Press.

R Core Team. (2018). R: A language and environment for statistical computing. Vienna, Austria: R Foundation for Statistical Computing. Retrieved January 1, 2019, from www.R-project.org

Rodenbusch, S. E., Hernandez, P. R., Simmons, S. L., \& Dolan, E. L. (2016). Early engagement in course-based research increases graduation rates and completion of science, engineering, and mathematics degrees. CBE-Life Sciences Education, 15(2), ar20.

Russell, C. B., \& Weaver, G. C. (2011). A comparative study of traditional, inquiry-based, and research-based laboratory curricula: Impacts on understanding of the nature of science. Chemistry Education Research and Practice, 12(1), 57-67

Sarmah, S., Chism, G. W., III, Vaughan, M. A., Muralidharan, P., Marrs, J. A., \& Marrs, K. A. (2016). Using zebrafish to implement a course-based undergraduate research experience to study teratogenesis in two biology laboratory courses. Zebrafish, 13(4), 293-304.

Seidel, S. B., \& Tanner, K. D. (2013). "What if students revolt?"-Considering student resistance: Origins, options, and opportunities for investigation. CBE-Life Sciences Education, 12(4), 586-595

Shibley, I. A., Jr, \& Zimmaro, D. M. (2002). The influence of collaborative learning on student attitudes and performance in an introductory chemistry laboratory. Journal of Chemical Education, 79(6), 745

Shortlidge, E. E., Bangera, G., \& Brownell, S. E. (2015). Faculty perspectives on developing and teaching course-based undergraduate research experiences. BioScience, 66(1), 54-62.

Spell, R. M., Guinan, J. A., Miller, K. R., \& Beck, C. W. (2014). Redefining authentic research experiences in introductory biology laboratories and barriers to their implementation. CBE-Life Sciences Education, 13(1) $102-110$

Stains, M., Harshman, J., Barker, M. K. Chasteen, S. V., Cole, R, DeChenne-Peters, S. E., ... \& Levis-Fitzgerald, M. (2018). Anatomy of STEM teaching in North American universities. Science, 359(6383), 1468-1470.

Stains, M., Pilarz, M., \& Chakraverty, D. (2015). Short and long-term impacts of the Cottrell scholars collaborative new faculty workshop. Journal of Chemical Education, 92(9), 1466-1476

Szteinberg, G. A., \& Weaver, G. C. (2013). Participants' reflections two and three years after an introductory chemistry course-embedded research experience. Chemistry Education Research and Practice, 14(1), 23-35.

Trigwell, K., \& Prosser, M. (2004). Development and use of the approaches to teaching inventory. Educational Psychology Review, 16(4), 409-424.

Velasco, J. B., Knedeisen, A., Xue, D., Vickrey, T. L., Abebe, M., \& Stains, M. (2016). Characterizing instructional practices in the laboratory: The Laboratory Observation Protocol for Undergraduate STEM. Journal of Chemical Education, 93(7), 1191-1203.

Watkins, J., \& Mazur, E. (2013). Retaining students in science, technology, engineering, and mathematics (STEM) majors. Journal of College Science Teaching, 42(5), 36-41.

Wubbels, T., \& Brekelmans, M. (2005). Two decades of research on teacherstudent relationships in class. International Journal of Educational Research, 43(1-2), 6-24.

Xu, H., \& Talanquer, V. (2013). Effect of the level of inquiry on student interactions in chemistry laboratories. Journal of Chemical Education, 90(1) $29-36$. 